\title{
Promoters of and barriers to cervical cancer screening in a rural setting in Tanzania
}

\author{
Powell Perng a,b ${ }^{\text {a, Wei Perng }}{ }^{c}$, Twalib Ngoma ${ }^{d}$, Crispin Kahesa $^{d}$, Julius Mwaiselage ${ }^{\mathrm{d}}$, \\ Sofia D. Merajver ${ }^{\text {a,b,c,* }}$, Amr S. Soliman ${ }^{\text {e }}$ \\ a Center for Global Health, University of Michigan, Ann Arbor, USA \\ b Department of Internal Medicine, University of Michigan Medical School, Ann Arbor, USA \\ c Department of Epidemiology, University of Michigan School of Public Health, Ann Arbor, USA \\ d Ocean Road Cancer Institute, Dar es Salaam, Tanzania \\ e Department of Epidemiology, University of Nebraska Medical Center, Omaha, USA
}

\section{A R T I C L E I N F O}

\section{Article history:}

Received 28 March 2013

Accepted 22 August 2013

\section{Keywords:}

Barriers

Cervical cancer

Low-income countries

Rural

Screening

\begin{abstract}
A B S T R A C T
Objective: To investigate promoters and barriers for cervical cancer screening in rural Tanzania. Methods: We interviewed 300 women of reproductive age living in Kiwangwa village, Tanzania. The odds of attending a free, 2-day screening service were compared with sociodemographic variables, lifestyle factors, and knowledge and attitudes surrounding cervical cancer using multivariable logistic regression. Results: Compared with women who did not attend the screening service $(\mathrm{n}=195)$, women who attended $(\mathrm{n}=105)$ were older $(\mathrm{OR} 4.29$; $95 \% \mathrm{CI}, 1.61-11.48$, age $40-49$ years versus $20-29$ years), listened regularly to the radio (OR 24.76 ; $95 \% \mathrm{CI}$, 11.49-53.33, listened to radio 1-3 times per week versus not at all), had a poorer quality of life (OR 4.91; CI, 1.96-12.32, lowest versus highest score), had faced cost barriers to obtaining health care in the preceding year (OR 2.24; 95\% CI, 1.11-4.53, yes versus no), and held a more positive attitude toward cervical cancer screening (OR 4.64; 95\% CI, 1.39-15.55, least versus most averse). Conclusion: Efforts aimed at improving screening rates in rural Tanzania need to address both structural and individual-level barriers, including knowledge and awareness of cervical cancer prevention, cost barriers to care, and access to health information.

(c) 2013 International Federation of Gynecology and Obstetrics. Published by Elsevier Ireland Ltd. All rights reserved.
\end{abstract}

\section{Introduction}

Cervical cancer disproportionately afflicts women living in poverty [1]. Although the disease is largely preventable, over half a million women worldwide develop invasive cervical cancer each year, the majority of whom reside in low- and middle-income countries [2]. Of the 275000 women who die annually from cervical cancer, 80\% live in low-income countries [3]. Tanzania, one of the poorest countries in the world, has an incidence rate that is 1.6 times the average rate in East Africa, the region with the highest cervical cancer incidence rate on the continent [4].

The method of visual inspection with acetic acid (VIA) has been championed as a viable, low-cost alternative to the Pap smear for the early detection of cervical cancer in resource-poor settings [5]. Since 2002, the Ocean Road Cancer Institute in Dar es Salaam, currently the only specialized cancer hospital in Tanzania, has helped to expand VIA services throughout the country [6,7]. Screening services remain limited, however, with only 12 of the 21 regions having access to at

\footnotetext{
* Corresponding author at: 1500 East Medical Center Drive, Ann Arbor, MI 48105, USA. Tel.: +1 734936 6884; fax: +1 7349367376.

E-mail address: smerajve@umich.edu (S.D. Merajver).
}

least 1 health center providing VIA [8]. Moreover, it is estimated that as little as $5 \%$ of the target population in Tanzania, women $30-50$ years of age, have ever been screened, and reports from referral hospitals reveal that the vast majority of cervical cancer patients are still presenting at late stages of the disease [6,9-11].

Screening uptake and disease outcomes are generally worse in rural areas compared with urban areas because the rural population is substantially poorer and access to health services is logistically more difficult $[1,12]$. Although expansion efforts have brought cervical cancer screening (CCS) to new regions, with 74 active screening sites as of March 2012, nearly all active sites are situated in urban communities, which comprise less than a quarter of Tanzania's population $[8,13]$. Considering that over $75 \%$ of the women of reproductive age live in rural communities without ready access to CCS, the true burden of cervical cancer incidence and mortality is likely to be greater among underserved rural women than the national estimates suggest.

Limited access to CCS in rural communities combined with low countrywide screening rates has prompted our multidisciplinary group to investigate impactable promoters and barriers to CCS in rural areas. Our overarching hypotheses are that low use of CCS is attributable to both structural factors, such as cost barriers and access to health information, and individual-level factors, such as disease awareness and health practices. Factors affecting uptake of CCS among underserved women in a 
specific rural site in Tanzania are presented here to help better inform future CCS programs tailored to rural settings.

\section{Materials and methods}

The present study was conducted in Kiwangwa, Tanzania, a rural village located $110 \mathrm{~km}$ northwest of Dar es Salaam in the Bagamoyo District. Bagamoyo is comprised of 102 villages and is one of 6 districts in the coastal region of Tanzania [13]. We chose Kiwangwa because it was accessible to us from Dar es Salaam, and its age and sex distribution as well as infrastructure and sociodemographics were comparable with that in other rural villages in the district [13]. Its 9145 residents (4766 women, 4379 men) and 2351 households are distributed over 9 hamlets [14]. Approximately $30 \%$ of women in Kiwangwa are 30 years of age or older-the recommended age at which seronegative women in Tanzania should begin triennial screening for cervical cancer $[13,15]$. The vast majority of the villagers are farmers, speak only Kiswahili, and do not have electricity or running water. The average daily wage for a laborer in Kiwangwa is 2950 Tanzanian shillings, the equivalent of US \$1.85 [14].

The village has a health dispensary that provides basic outpatient care for sick children and adults, maternal and child health services, and testing and treatment for major infectious diseases. The dispensary employs 1 physician, 2 nurses, 3 health orderlies, and 2 community health workers. The dispensary does not offer CCS.

A 25-minute, interviewer-administered questionnaire was designed referencing concepts from previously validated survey instruments and focusing on individual and structural factors that could influence screening use $[10,16,17]$. We developed the survey in English with our Tanzanian team members, and it was translated into Kiswahili with the assistance of a professional language instructor. Approval to conduct the present study was obtained from the Institutional Review Boards at the University of Michigan, Ann Arbor, MI, USA, and the National Institute for Medical Research in Dar es Salaam. Two trained community health workers were hired from the Kiwangwa health dispensary to assist with administering the interviews in Kiswahili. Following 50 pretest interviews, minor wording changes were made to improve question comprehension. We met with the community health workers on a weekly basis to supervise data collection and monitor survey quality.

Basic sociodemographic information was collected, including age, years of residence, marital status, parity, and education level. General health practices, which included habit of treating drinking water, use of cigarettes and oral contraceptives, and access to health services, were also examined. Index variables were created to assess constructs-quality of life (QOL), decision-making autonomy, and knowledge and attitudinal constructs-that the team decided would be best measured using multiple questions (Supplementary Material S1).

We interviewed 300 women from March 14 to June 8, 2012. Of these, 202 women were recruited at home from March 14 to May 8, 2012; 98 women were recruited during an organized screening intervention from June 7 to 8, 2012 (Fig. 1).

To ensure proportional representation from each hamlet during home interviews, convenience quota sampling was used to recruit participants in proportion to the number of households in each hamlet. We then randomly recruited 1 woman who was 25 years or older from each household. Each participant was read a text explaining the study aims and provided written consent. A minimum of 15 minutes was set aside after each interview to educate the participant and her family about cervical cancer. Only 6 women declined to be interviewed because of household work.

In June 2012, we sponsored a 2-day CCS service at the Kiwangwa health dispensary. A week prior to the service, flyers advertising the service were posted at the local school and marketplace. Motorcycle messengers were hired to disseminate the message via megaphone through each hamlet on 3 separate days prior to the service. During the service, women were recruited for interviews at random from the waiting area. The survey, consent forms, and interview protocols

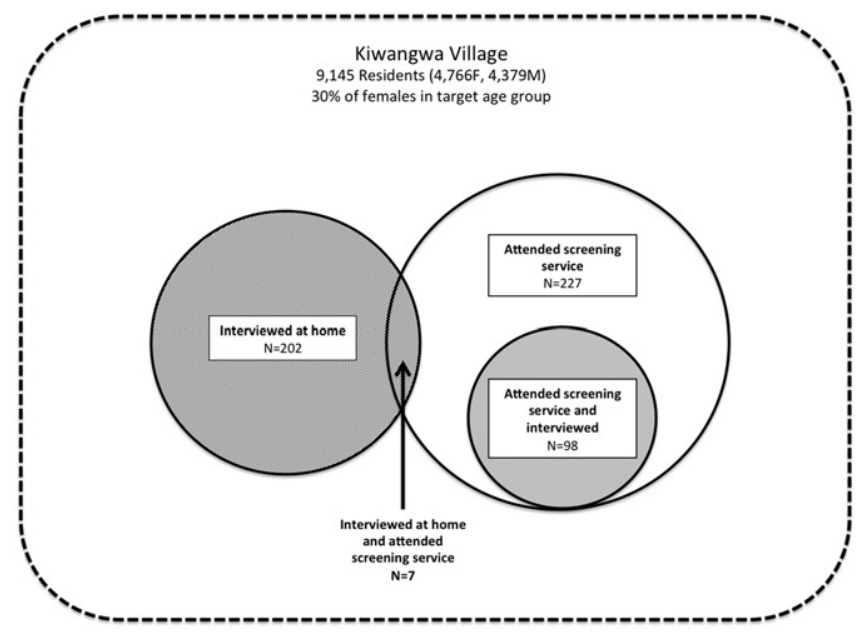

Fig. 1. Diagram of recruitment strategy. Between March and May 2012, 202 women were interviewed at home; in June 2012, 98 women were interviewed at the 2-day screening service. Seven women who had been interviewed at home also attended the screening service, and their data were pooled with those for the 98 women interviewed at the service. In total, 227 women attended the service from the village. Abbreviations: F, female; $\mathrm{M}$, male.

were the same as those used in the home interviews, the only additional requirement being that women could not have been previously interviewed during home visits. All women who were approached agreed to participate.

The final analytic sample comprised 300 women, 105 of whom attended the screening service (Fig. 1). Of the women who attended the screening, 7 had participated in the home interviews, and the remaining 98 were interviewed on-site at the CCS service. In the analysis, data for the 7 home-interviewed women were pooled with those for the 98 women who went directly to the service.

To identify predictors of screening, the odds of screening attendance were examined with respect to sociodemographic and lifestyle variables. Odds ratios and 95\% confidence intervals (CIs) were compared across categories of these variables using logistic regression. The significance of these associations was assessed using the Wald test for a main effect. For ordinal variables, a test of linear trend was obtained.

Next, we assessed the relation between the odds of attendance and women's knowledge and perceptions surrounding cervical cancer; attitudes toward screening; attitudes toward the health system; basic disease knowledge; decision-making autonomy; and QOL. Each domain was measured using multiple questions with responses recorded either as "Yes/No" or as a score on a 3- or 5-level Likert scale. Three-level indices were then created based on these scores (Supplementary Material S1). To assess the statistical significance of the associations, we tested for a linear trend across levels of each index.

Finally, to construct the multivariable model, a stepwise selection procedure was used to determine the final set of indices to retain in the model. The fully loaded model included all indices and sociodemographic and lifestyle variables that were significant in the univariate analysis at $P<0.05$. In these models, we deliberately avoided adjustment for covariates that could be on the causal pathway between the indices and attending screening. Excluding the 7 women interviewed at home produced no difference in the direction, magnitude, or statistical significance of the results. All analyses were carried out with SAS version 9.2 (SAS Institute, Cary, NC, USA).

\section{Results}

In total, 227 women from the village attended the screening service and $16(7.0 \%)$ screened positive for pre-cancerous lesions. These women were contacted the following month and were provided with free cryotherapy surgery treatment. Of the women who attended 
the service, $7 / 227$ (3.1\%) had previously been interviewed at home, representing 3.5\% of the home-interview group; 98/227 (43.2\%) women were interviewed during the screening service (Fig. 1).

In the univariate analysis (Table 1), the odds of attending screening were related to age, with women in the 40-49-year age group having a 2.5 (95\% CI, 1.26-4.98) times higher odds of attending screening than those 20-29 years of age. The odds of screening were also positively related to the number of years at the current residence, the education level, attendance of regular health check-ups, and radio use frequency. Women who had experienced financial barriers to obtaining health care in the preceding year had a $72 \%$ higher odds of attending screening than those who had not experienced health-care-related financial issues $(P=0.03)$.

The QOL score was negatively associated with screening attendance (Table 2). In comparison with those with the highest QOL score, women with the lowest score had a 2.73 times greater odds of attending screening $(P=0.006)$. Cervical cancer awareness, risk factor knowledge, attitude toward screening, and knowledge about screening were each positively related to the odds of screening (Table 2).

In the multivariable analysis (Table 3), the positive relations of age, recent financial issues with health care, radio use frequency, and attitude toward CCS remained apparent. Additionally, women with the lowest QOL score were nearly 5 times more likely to attend screening than those in the highest score $(P$ trend $=0.001)$.

\section{Discussion}

To explore factors that influence CCS in rural settings, a random sample of women living in rural households was compared with women from the same village who attended a 2-day, inexpensively advertised CCS intervention. The results indicate that in addition to knowledge and attitudes regarding cervical cancer, broader social and structural factors substantially influence a woman's decision to obtain screening.

Age was positively associated with the odds of screening participation, with women 40-49 years of age demonstrating the highest odds of attendance. This finding is consistent with previous studies conducted in India and Sub-Saharan Africa $[18,19]$. The relation could be attributable to older women having had more contact with reproductive health services as a result of longer fertility histories [20].

Women who reported having experienced financial barriers to obtaining medical care within the preceding year were more likely to attend the service than their counterparts. In a health system where patients often need to purchase their own supplies, it is possible that the women who routinely accessed health services were more likely to face cost barriers than those who did not visit the health clinics at all. This rationale would concur with the positive association between attending regular health check-ups and screening attendance. It is also possible that women who had previously experienced cost barriers to care were more likely to appreciate a service where all costs were defrayed by the present study team, indicating that when cost barriers to screening are removed, the women who are less able to afford health care are more likely to participate.

In a similar vein, women who reported a poorer QOL were more likely to attend the service. This challenged the prediction that domestic priorities could be particularly salient barriers to screening for rural women, who typically spend more time performing reproductive, community, and household work than urban women [21-23]. The perceived absence of ill health, however, has also been reported as a deterrent to screening [21]. Hence, it is possible that in the present population, the women with a poorer QOL were more receptive to the health intervention than women who felt they were already healthy.

As hypothesized, women who held more positive attitudes toward screening and had greater knowledge of cervical cancer were substantially more likely to attend the service. Awareness of other diseases, however, such as HIV, tuberculosis, and malaria, was unrelated to screening attendance, which indicates that being health-literate in
Table 1

Odds ratio of attending cervical cancer screening according to sociodemographic characteristics and general health practices among women from Kiwangwa, Tanzania.

\begin{tabular}{|c|c|c|c|c|}
\hline Parameter & $\begin{array}{l}\text { Total } \\
\text { number } \\
(\mathrm{n}=300)\end{array}$ & $\begin{array}{l}\text { Attended } \\
\text { screening } \\
(\mathrm{n}=105)^{\mathrm{a}}\end{array}$ & OR $(95 \% \mathrm{CI})$ & $P$ value ${ }^{\mathrm{b}}$ \\
\hline Age & & & & 0.005 \\
\hline $20-29$ y & 101 & $26(25.7)$ & Reference & \\
\hline $30-39 y$ & 104 & $42(40.4)$ & $1.95(1.08-3.54)$ & \\
\hline $40-49 y$ & 56 & $26(46.4)$ & $2.50(1.26-4.98)$ & \\
\hline$\geq 50 \mathrm{y}$ & 32 & $5(15.6)$ & $0.53(0.19-1.53)$ & \\
\hline Missing & 7 & $6(85.7)$ & - & \\
\hline $\begin{array}{l}\text { Currently married or } \\
\text { cohabiting }\end{array}$ & & & & 0.24 \\
\hline Yes & 216 & $80(37.0)$ & $1.39(0.81-2.39)$ & \\
\hline No & 84 & $25(29.8)$ & Reference & \\
\hline Years at current residence & & & & 0.04 \\
\hline 0 to $<2$ & 64 & $15(23.4)$ & Reference & \\
\hline 2 to $<4$ & 80 & $29(36.3)$ & $1.86(0.89-3.88)$ & \\
\hline 4 to $<9$ & 77 & $25(32.5)$ & $1.57(0.74-3.32)$ & \\
\hline$\geq 9$ & 77 & $36(46.8)$ & $2.87(1.38-5.96)$ & \\
\hline Missing & 2 & $0(0.0)$ & - & \\
\hline Education level & & & & $<0.001$ \\
\hline No formal education & 62 & $4(6.5)$ & Reference & \\
\hline $\begin{array}{l}\text { Some primary } \\
\text { education }\end{array}$ & 23 & $5(21.7)$ & $4.03(0.98-16.62)$ & \\
\hline $\begin{array}{l}\text { Complete primary } \\
\text { or higher }\end{array}$ & 193 & $74(38.3)$ & $9.02(3.14-25.87)$ & \\
\hline Missing & 22 & $22(100.0)$ & - & \\
\hline Parity & & & & 0.35 \\
\hline $0-2$ & 98 & $33(33.7)$ & Reference & \\
\hline $3-4$ & 96 & $38(39.6)$ & $1.29(0.72-2.32)$ & \\
\hline $5-6$ & 58 & $15(25.9)$ & $0.69(0.33-1.41)$ & \\
\hline$\geq 7$ & 47 & $18(38.3)$ & $1.22(0.59-2.52)$ & \\
\hline Missing & 1 & $1(100.0)$ & - & \\
\hline Treats drinking water & & & & 0.06 \\
\hline No & 209 & $66(31.6)$ & Reference & \\
\hline Yes & 91 & 39 (42.9) & $1.63(0.98-2.70)$ & \\
\hline Oral contraceptive use & & & & 0.15 \\
\hline No & 162 & $51(31.5)$ & Reference & \\
\hline Yes & 137 & $54(39.4)$ & $1.42(0.88-2.28)$ & \\
\hline Missing & 1 & $0(0.0)$ & - & \\
\hline Ever smoked & & & & 0.56 \\
\hline No & 291 & $102(35.1)$ & $1.62(0.32-8.16)$ & \\
\hline Yes & 8 & $2(25.0)$ & Reference & \\
\hline Missing & 1 & $1(100.0)$ & - & \\
\hline $\begin{array}{l}\text { Attends regular physical } \\
\text { check-up }\end{array}$ & & & & $<0.001$ \\
\hline Yes & 226 & $94(41.6)$ & $4.08(2.04-8.15)$ & \\
\hline No & 74 & $11(14.9)$ & Reference & \\
\hline $\begin{array}{l}\text { Faced recent cost barriers } \\
\text { to health care }{ }^{\mathrm{a}}\end{array}$ & & & & 0.03 \\
\hline No & 171 & $51(29.8)$ & Reference & \\
\hline Yes & 128 & $54(42.2)$ & $1.72(1.06-2.78)$ & \\
\hline Missing & 1 & $0(0.0)$ & - & \\
\hline Access to health clinic & & & & 0.37 \\
\hline 1 (good) & 144 & $54(37.5)$ & Reference & \\
\hline 2 & 101 & $30(29.7)$ & $0.70(0.41-1.21)$ & \\
\hline 3 (poor) & 54 & $21(38.9)$ & $1.06(0.56-2.02)$ & \\
\hline Missing & 1 & $0(0.0)$ & - & \\
\hline Radio use frequency & & & & $<0.001$ \\
\hline Not at all & 195 & $28(14.4)$ & Reference & \\
\hline$<1$ time/week & 19 & $11(57.9)$ & $8.20(3.03-22.17)$ & \\
\hline 1-3 times/week & 73 & $57(78.1)$ & $21.24(10.72-42.10)$ & \\
\hline$\geq 4$ times/week & 13 & $9(69.2)$ & $13.42(3.87-46.55)$ & \\
\hline Owns a radio & & & & 0.14 \\
\hline Yes & 229 & $85(37.1)$ & $1.45(0.82-2.65)$ & \\
\hline No & 71 & $20(28.6)$ & Reference & \\
\hline Owns a telephone & & & & 0.21 \\
\hline Yes & 202 & $75(37.0)$ & $1.34(0.80-2.24)$ & \\
\hline No & 98 & $30(30.6)$ & Reference & \\
\hline Access to transportation & & & & 0.23 \\
\hline Yes & 201 & $75(37.3)$ & $1.37(0.82-2.29)$ & \\
\hline No & 99 & $30(30.3)$ & Reference & \\
\hline
\end{tabular}

Abbreviations: CI, confidence interval; OR, odds ratio.

a Values are given as number (percentage).

b From the Wald test of main effect. $P$ values represent a test of trend for years at current residence, education level, parity, access to health clinic, and radio use frequency. 
Table 2

Odds ratio of attending cervical cancer screening according to perceptions, knowledge, and attitudes surrounding cervical cancer and cervical cancer screening among women from Kiwangwa, Tanzania. ${ }^{a}$

\begin{tabular}{|c|c|c|c|c|}
\hline Parameter & $\begin{array}{l}\text { Total } \\
\text { number } \\
(n=300)\end{array}$ & $\begin{array}{l}\text { Attended } \\
\text { screening } \\
(\mathrm{n}=105)^{\mathrm{b}}\end{array}$ & OR $(95 \% \mathrm{CI})$ & $P$ value \\
\hline Quality of life & & & & 0.006 \\
\hline 1 (poorest) & 126 & 49 (38.9) & $2.73(1.44-5.17)$ & \\
\hline 2 & 84 & $39(46.4)$ & $3.72(1.89-7.35)$ & \\
\hline 3 (best) & 90 & $17(18.9)$ & Reference & \\
\hline Basic disease awareness & & & & 0.69 \\
\hline 1 (lowest) & 6 & $2(33.3)$ & Reference & \\
\hline 2 & 26 & $8(30.8)$ & $0.89(0.13-5.89)$ & \\
\hline 3 (highest) & 268 & $95(35.5)$ & $1.10(0.20-6.11)$ & \\
\hline Cervical cancer awareness & & & & $<0.001$ \\
\hline 1 (lowest) & 57 & $8(14.0)$ & Reference & \\
\hline 2 & 72 & $13(18.1)$ & $1.35(0.52-3.52)$ & \\
\hline 3 (highest) & 160 & $74(46.3)$ & $5.27(2.35-11.84)$ & \\
\hline Missing & 11 & $10(90.9)$ & - & \\
\hline $\begin{array}{l}\text { Cervical cancer risk factor } \\
\text { knowledge }\end{array}$ & & & & $<0.001$ \\
\hline 1 (poorest) & 92 & $13(14.1)$ & Reference & \\
\hline 2 & 105 & $36(34.3)$ & $3.17(1.56-6.46)$ & \\
\hline 3 (best) & 103 & $56(54.4)$ & $7.24(3.58-14.62)$ & \\
\hline $\begin{array}{l}\text { Cervical cancer screening } \\
\text { attitude }\end{array}$ & & & & $<0.001$ \\
\hline 1 (most averse) & 34 & $7(20.6)$ & Reference & \\
\hline 2 & 123 & $30(24.4)$ & $1.24(0.49-3.15)$ & \\
\hline 3 (least averse) & 142 & 68 (47.9) & $3.54(1.45-8.67)$ & \\
\hline Missing & 1 & $0(0.0)$ & - & \\
\hline $\begin{array}{l}\text { Cervical cancer screening } \\
\text { knowledge }\end{array}$ & & & & $<0.001$ \\
\hline 1 (poorest) & 116 & $26(22.4)$ & Reference & \\
\hline 2 & 130 & $51(39.2)$ & $2.24(1.28-3.92)$ & \\
\hline 3 (best) & 54 & $28(51.9)$ & $3.73(1.87-7.43)$ & \\
\hline $\begin{array}{l}\text { Perceived threat of cervical } \\
\text { cancer }\end{array}$ & & & & 0.18 \\
\hline 1 (lowest) & 31 & $11(35.5)$ & Reference & \\
\hline 2 & 59 & $13(22.0)$ & $0.51(0.20-1.34)$ & \\
\hline 3 (highest) & 210 & $81(38.6)$ & $1.14(0.52-2.51)$ & \\
\hline Decision-making autonomy & & & & 0.96 \\
\hline 1 (lowest) & 150 & $53(35.3)$ & Reference & \\
\hline 2 & 82 & $28(34.2)$ & $0.95(0.54-1.67)$ & \\
\hline 3 (highest) & 68 & $24(35.3)$ & $1.00(0.55-1.82)$ & \\
\hline
\end{tabular}

a See Supplementary Material S1 for index components.

b Values are given as number (percentage).

c Represents a test for linear trend in which the ordinal indicator was entered into a logistic regression model as a continuous variable.

other disease topics does not necessarily confer health literacy in the realm of cervical cancer. Thus, targeted disease education and outreach efforts aimed at cancer-prevention literacy are still critical to improving screening use.

Lastly, and of particular relevance to building health literacy in rural communities, a strong association was observed between listening to the radio on a regular basis and screening attendance. The radio, which has been reported as a prime source of cervical cancer information for underserved populations, was highly adopted in the present setting, with over $75 \%$ of surveyed households owning a radio [24]. These data indicate that public-health radio announcements on cancer screening, such as those broadcasted by the Medical Women Association of Tanzania, can be an effective means for mobilizing rural women to seek screening.

The present study has several strengths. First, the study was conducted in a representative rural setting where women were recruited directly from the community; this approach helps eliminate sampling bias that can arise from recruiting subjects exclusively at health centers. Secondly, we examined knowledge and attitudes as well as structural factors so as to inform a broader understanding of screening barriers in rural settings. Third, the study design enabled the assessment of differences between women who actively attended the
Table 3

Adjusted odds ratios of attending cervical cancer screening according to social and structural factors among women from Kiwangwa, Tanzania $(\mathrm{n}=300)$.

\begin{tabular}{|c|c|c|}
\hline Parameter & $\begin{array}{l}\text { Adjusted OR ( } 95 \% \mathrm{CI}) \\
\text { of screening attendance }\end{array}$ & $P$ value ${ }^{c}$ \\
\hline Age $^{a}$ & & 0.02 \\
\hline $20-29$ y & Reference & \\
\hline $30-39 y$ & $1.88(0.83-4.25)$ & \\
\hline $40-49 y$ & $4.29(1.61-11.48)$ & \\
\hline$\geq 50 \mathrm{y}$ & $1.15(0.31-4.23)$ & \\
\hline Faced recent cost barriers to health care ${ }^{a}$ & & 0.03 \\
\hline No & Reference & \\
\hline Yes & $2.24(1.11-4.53)$ & \\
\hline Radio use frequency ${ }^{\mathrm{b}}$ & & $<0.001$ \\
\hline Not at all & Reference & \\
\hline Once/week & $11.45(3.80-34.64)$ & \\
\hline 1-3 times/week & $24.76(11.49-53.33)$ & \\
\hline$\geq 4$ times/week & $17.40(4.57-66.24)$ & \\
\hline Quality of life $\mathrm{a}^{\mathrm{a}}$ & & 0.001 \\
\hline 1 (Poorest) & $4.91(1.96-12.32)$ & \\
\hline 2 & $3.78(1.48-9.62)$ & \\
\hline 3 (Best) & Reference & \\
\hline Cervical cancer screening attitude $\mathrm{a}^{\mathrm{a}}$ & & 0.001 \\
\hline 1 (most averse) & Reference & \\
\hline 2 & $1.62(0.48-5.49)$ & \\
\hline 3 (least averse) & $4.64(1.39-15.55)$ & \\
\hline
\end{tabular}

Abbreviations: $\mathrm{CI}$, confidence interval; OR, odds ratio.

a From a stepwise model selection procedure with a logistic regression model where screening attendance was the outcome and predictors included age, experience of healthcare financial issues in the preceding year, radio use frequency, basic needs, and cervical cancer screening attitude.

b From a stepwise model selection procedure with a logistic regression model where screening attendance was the outcome and predictors included age, experience of healthcare financial issues in the preceding year, and radio use frequency.

c Represents a test for linear trend in which an indicator for an ordinal category of the index was entered into a logistic regression model as a continuous variable for all variables except "age" and "recent financial issues with health care" (Wald test).

screening service and those who abstained. Lastly, beyond following a research agenda, our team was also instrumental in procuring disease education, screening, and treatment for a high-risk population at need for these services.

The present study also had some limitations. First, although Kiwangwa is considered to be representative of other villages in the district, sampling from a single site limits the generalizability of the present findings to other rural settings. Second, the use of convenience quota sampling within the village encouraged subject recruitment from the most accessible homes. Third, a 2-day screening intervention might not have fully captured all women who had wished to attend.

In summary, individual-level factors, including age, QOL, knowledge and awareness about disease, as well as structural factors, such as access to media and cost barriers to health care, were identified as modifiable predictors of CCS use among women of reproductive age in rural Tanzania. Continued research in the area of rural health outcomes is needed not only to better understand the situation faced by rural women but also to inform the rationale of cancer prevention and treatment services for women with the lowest resources and access.

Supplementary data to this article can be found online at http://dx. doi.org/10.1016/j.ijgo.2013.05.026.

\section{Acknowledgments}

The present study was supported by a Fulbright Program grant sponsored by the Bureau of Educational and Cultural Affairs of the United States Department of State and administered by the Institute of International Education. The study was also supported by the Cancer Epidemiology Education in Special Populations program of the University of Nebraska (Omaha, NE, USA; grant R25 CA11 2383), the Avon Foundation (A.S.S., S.D.M), and the Breast Cancer Research Foundation (S.D.M). 


\section{Conflict of interest}

The authors have no conflicts of interest.

\section{References}

[1] Palacio-Mejía LS, Rangel-Gómez G, Hernández-Avila M, Lazcano-Ponce E. Cervical cancer, a disease of poverty: mortality differences between urban and rural areas in Mexico. Salud Publica Mex 2003;45(Suppl. 3):S315-25.

[2] Thun MJ, DeLancey JO, Center MM, Jemal A, Ward EM. The global burden of cancer: priorities for prevention. Carcinogenesis 2010;31(1):100-10

[3] Ferlay J, Shin HR, Bray F, Forman D, Mathers C, Parkin DM. Estimates of worldwide burden of cancer in 2008: GLOBOCAN 2008. Int J Cancer 2010;127(12): 2893-917.

[4] WHO/ICO Information Centre on HPV and Cervical Cancer. Human Papillomavirus and Related Cancers in Tanzania. Summary Report. Published 2010.

[5] Sankaranarayanan R, Budukh AM, Rajkumar R. Effective screening programmes for cervical cancer in low- and middle-income developing countries. Bull World Health Organ 2001;79(10):954-62.

[6] Mwaiselage J. Outreach of Cervical Cancer Prevention Program in Tanzania: Achievements and Challenges. Published 2010.

[7] Sankaranarayanan R, Gaffikin L, Jacob M, Sellors J, Robles S. A critical assessment of screening methods for cervical neoplasia. Int J Gynecol Obstet 2005;89(Suppl. 2): S4-S12.

[8] Andrews L. Standard Operating Procedures for Implementation of Cervical Cancer Screening and Early Treatment Program. Published 2012.

[9] Mosha D, Mahande M, Ahaz J, Mosha M, Njau B, Kitali B, et al. Factors associated with management of cervical cancer patients at KCMC Hospital, Tanzania: a retrospective cross-sectional study. Tanzan J Health Res 2009;11(2):70-4.

[10] Peters LM, Soliman AS, Bukori P, Mkuchu J, Ngoma T. Evidence for the need of educational programs for cervical screening in rural Tanzania. J Cancer Educ 2010;25(2):153-9.
[11] Kazaura MR, Kombe D, Yuma S, Mtiro H, Mlawa G. Health seeking behavior among cancer patients attending Ocean Road Cancer Institute, Tanzania. East Afr J Public Health 2007;4(1):19-22.

[12] Watkins MM, Gabali C, Winkleby M, Gaona E, Lebaron S. Barriers to cervical cancer screening in rural Mexico. Int J Gynecol Cancer 2002;12(5):475-9.

[13] Central Census Office. 2002 Population and Housing Census: Village and street statistics age and sex distribution. Dar es Salaam: National Bureau of Statistics; 2003.

[14] Rashidi K. Takwimu za Kijiij (Village Data) Kiwangwa. Published 2012.

[15] The United Republic of Tanzanian Ministry of Health and Social Welfare. Tanzania Service Delivery Guidelines for Cervical Cancer Prevention and Control. Published 2011.

[16] Abotchie PN, Shokar NK. Cervical cancer screening among college students in ghana: knowledge and health beliefs. Int J Gynecol Cancer 2009;19(3):412-6.

[17] Nguyen TT, McPhee SJ, Nguyen T, Lam T, Mock J. Predictors of cervical Pap smear screening awareness, intention, and receipt among Vietnamese-American women. Am J Prev Med 2002;23(3):207-14.

[18] Roy B, Tang TS. Cervical cancer screening in Kolkata, India: beliefs and predictors of cervical cancer screening among women attending a women's health clinic in Kolkata, India. J Cancer Educ 2008;23(4):253-9.

[19] Gichangi P, Estambale B, Bwayo J, Rogo K, Ojwang S, Opiyo A, et al. Knowledge and practice about cervical cancer and Pap smear testing among patients at Kenyatta National Hospital, Nairobi, Kenya. Int J Gynecol Cancer 2003;13(6):827-33.

[20] Lazcano-Ponce EC, Moss S, Cruz-Valdez A de Ruíz PA, Martínez-León CJ, CasaresQueralt S, et al. The positive experience of screening quality among users of a cervical cancer detection center. Arch Med Res 2002;33(2):186-92.

[21] Fort VK, Makin MS, Siegler AJ, Ault K, Rochat R. Barriers to cervical cancer screening in Mulanje, Malawi: a qualitative study. Patient Prefer Adherence 2011;5:125-31.

[22] Logan L, Mcllfatrick S. Exploring women's knowledge, experiences and perceptions of cervical cancer screening in an area of social deprivation. Eur J Cancer Care (Engl) 2011;20(6):720-7.

[23] Inter-Agency Task Force on Rural Women, United Nations. Rural Women and the Millenium Development Goals. Published 2012.

[24] Tebeu PM, Major AL, Rapiti E, Petignat P, Bouchardy C, Sando Z, et al. The attitude and knowledge of cervical cancer by Cameroonian women; a clinical survey conducted in Maroua, the capital of Far North Province of Cameroon. Int J Gynecol Cancer 2008;18(4):761-5. 